\title{
ERRATUM
}

In: Appl Microbiol Biotechnol, Vol. 42, No. 2-3, pp. 432-439

Due to an unfortunate error, the drawings in Figures 1 and 2 of the following contribution have been incorrectly labelled:

Fradette S, Rho D, Samson R, LeDuy A:

\section{Microcalorimetry as a diagnostic and analytical tool for the assessment of biodegradation of 2,4-D in a liquid medium and in soil}

The correct presentations are as follows:

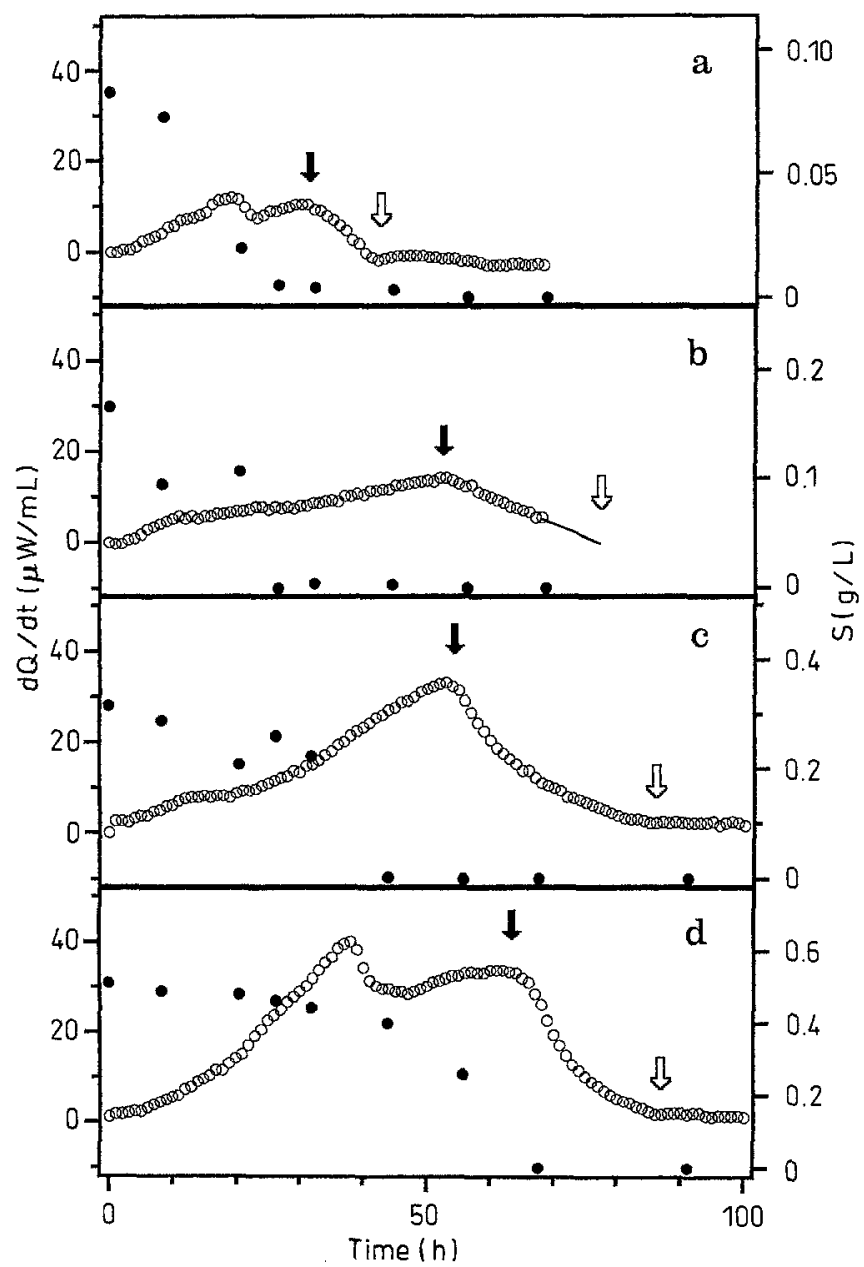

Fig. 1a-d Rate of heat evolved $(d \mathrm{Q} / d t)$ during the biodegradation of 2,4-dichlorophenoxyacetic acid (2,4-D) by Pseudomonas cepacia in a liquid medium at different initial concentrations of 2,4-D $\left(\mathrm{S}_{0}\right): 0$, $d \mathrm{Q} / d t ; \bullet$, residual $2,4-\mathrm{D}$ concentration $\mathrm{S} ; \rightarrow$, characteristic time $t_{1}$; $\Rightarrow$, characteristic time $t_{\mathrm{f} .}$ a $80 \mathrm{mg} / \mathrm{l} . \quad$ b $160 \mathrm{mg} / \mathrm{l}$. c $300 \mathrm{mg} / \mathrm{l}$. d $500 \mathrm{mg} / \mathrm{l}$

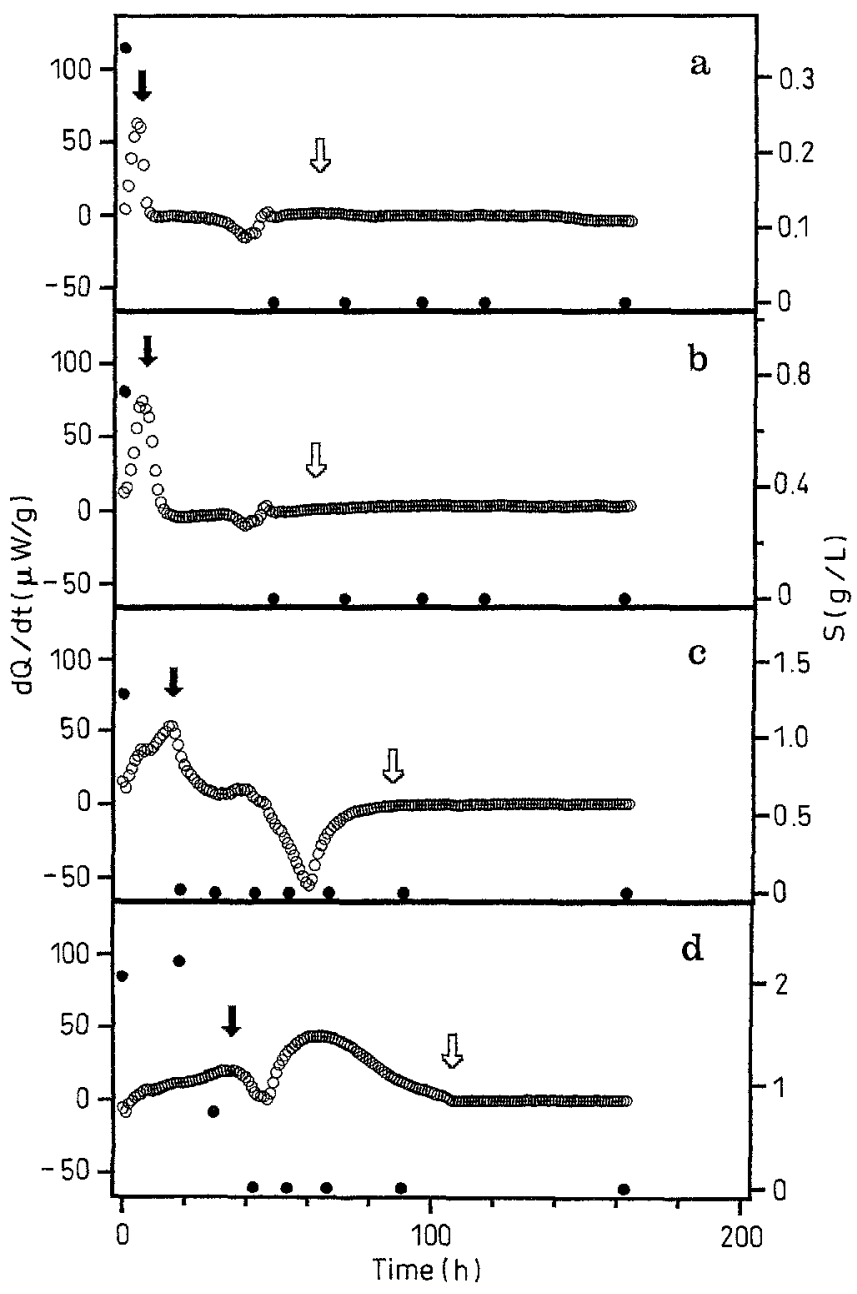

Fig. 2a-d Rate of heat evolved $(d \mathrm{Q} / d t)$ during the biodegradation of 2,4-D by $P$. cepacia in soil at different initial concentrations of 2,4-D $\left(\mathrm{S}_{0}\right)$ : for symbols, see Fig. 1 . a $85 \mathrm{mg} / \mathrm{kg}$. b $185 \mathrm{mg} / \mathrm{kg}$. c $300 \mathrm{mg} / \mathrm{kg}$. d $500 \mathrm{mg} / \mathrm{kg}$ 